\title{
Heat and chilling stress induce nucleolus morphological changes
}

\author{
Kohma Hayashi $^{1} \cdot$ Sachihiro Matsunaga ${ }^{1}$
}

Received: 19 May 2018 / Accepted: 12 February 2019 / Published online: 7 March 2019

(c) The Botanical Society of Japan and Springer Japan KK, part of Springer Nature 2019

\begin{abstract}
The nucleolus, where components of the ribosome are constructed, is known to play an important role in various stress responses in animals. However, little is known about the role of the plant nucleolus under environmental stresses such as heat and chilling stress. In this study, we analyzed nucleolus morphology by determining the distribution of newly synthesized rRNAs with an analog of uridine, 5-ethynyl uridine (EU). When EU was incorporated into the root of the Arabidopsis thaliana, EU signals were strongly localized in the nucleolus. The results of the short-term incorporation of EU implied that there is no compartmentation among the processes of transcription, processing, and construction of rRNAs. Nevertheless, under heat and chilling stress, EU was not incorporated into the center of the nucleolus. Morphological analyses using whole rRNA staining and differential interference contrast observations revealed speckled and round structures in the center of the nucleolus under heat and chilling stress, respectively.
\end{abstract}

Keywords Chilling stress $\cdot 5$-Ethynyl uridine $\cdot$ Heat stress $\cdot$ Nucleolus $\cdot$ Nucleolus cavity

\section{Introduction}

The nucleolus is the nuclear structure where rRNAs are synthesized and processed and ribonucleoproteins are assembled. Based on electron microscope observations, the nucleolus has three structures; the fibrillar center (FC), the dense fibrillar component (DFC), and the granular component (GC). The DFC region contains rRNA, the FC region contains RNA polymerases and their cofactors such as upstream binding factors, and the GC region is the site where ribonucleoproteins are assembled (as reviewed in Boisvert et al. 2007; Matsunaga et al. 2013; Sirri et al. 2008).

Many studies on animals have revealed that the nucleolus plays an important role in various stress responses (Reviewed in Boulon et al. 2010) such as DNA damage (AI-Baker et al. 2005; Cioce et al. 2006; Kruhlak et al. 2007; Rubbin et al. 2003), heat stress (Carmo-Fonseca et al. 1993; Handwerger et al. 2002; Rubbin et al. 2003), cold stress (Carmo-Fonseca et al. 1993), hypoxia stress (Mekhail et al. 2006; Rubbin et al. 2003), osmotic stress

Sachihiro Matsunaga

sachi@rs.tus.ac.jp

1 Department of Applied Biological Science Faculty of Science and Technology, Tokyo University of Science, 2641 Yamazaki, Noda, Chiba 278-8510, Japan
(Cioce et al. 2006), viral infection (Greco 2009; James et al. 2010; Morency et al. 2007; Rebelo et al. 1996) and nutrient stress (Andrade et al. 1993; Hoppe et al. 2009; Mayer et al. 2006; Tanaka et al. 2010). These stresses have been shown to induce morphological changes in the nucleolus and inhibit RNA polymerase activity, resulting in the release of secretion element(s) required for apoptosis or cell cycle arrest. A recent study showed that a secretion from the nucleolus is also involved in tumor suppression (Russo et al. 2017).

Various stresses trigger the p53 pathway to induce cell-cycle arrest, cell senescence, or apoptosis in animals. Arabidopsis thaliana (L.) Heynh. has no p53 homolog, but instead has the plant-specific transcription factor family NAC, whose members function in the pathways responsive to various cellular stresses (as reviewed in Ohbayashi and Sugiyama 2018). One NAC transcription factor, ANAC082, is induced under nucleolar stress and is associated with developmental alterations and cell proliferation defects (Ohbayashi et al. 2017).

5-Ethynyl uridine (EU) is an analog of uridine that can be taken up into newly synthesized RNAs. The click-iT reaction enables fluorescent molecules to bind to EU. A similar analog, 5-ethynyl-2'-deoxyuridine (EdU), has been widely used to tag fluorescent molecules to newly synthesized DNA in plants (Hayashi et al. 2013; Ichihashi et al. 2011; Katogany et al. 2010; Salic et al. 2008; Yokoyama 
et al. 2016). Recently, EU has been reported as a suitable molecule to stain newly synthesized RNAs in A. thaliana roots (Dvořáčková et al. 2018). Because rRNA are actively synthesized in the nucleolus (Pontvianne et al. 2013), visualization with EU allows analyses of the morphology and function of the nucleolus. In this study, we analyzed the relationship between environmental stress responses and nucleolar morphology by EU staining.

\section{Materials and methods}

\section{Plant material and EU incorporation}

5-day-old seedlings of $A$. thaliana (Col-0) were used in these experiments. The seedlings were incubated in liquid 1/2 MS (Murashige and Skoog) medium containing 1\% (w/v) sucrose and $1 \mathrm{mM}$ EU (Jena Bioscience, Jena, Germany) for $2 \mathrm{~h}$ in the dark at the following temperatures: $0^{\circ} \mathrm{C}$, $12{ }^{\circ} \mathrm{C}, 22^{\circ} \mathrm{C}, 30^{\circ} \mathrm{C}$, and $37^{\circ} \mathrm{C}$ for chilling and cold stresses, control conditions, and mild heat, and severe heat stresses, respectively. For osmotic stress, the liquid medium contained $200 \mathrm{mM} \mathrm{NaCl}$, and for actinomycin D (ActD) treatment, 5, 25, or $60 \mu \mathrm{M}$ Act $\mathrm{D}$ was added to the liquid medium $1 \mathrm{~h}$ before or at the same time as EU incorporation. For a time course experiment under heat stress, seedlings were incubated in the liquid medium for 30 and $60 \mathrm{~min}$. After the incubation, seedlings were fixed in $4 \%$ paraformaldehyde (PFA) in phosphate-buffered saline (PBS) for $30 \mathrm{~min}$. During fixation, the chambers were evaporated. The fixed seedlings were washed three times with $1 \times$ PBS, then incubated in $0.1 \%(\mathrm{v} / \mathrm{v})$ TritonX-100 in PBS for $30 \mathrm{~min}$. After washing the seedlings three times with $1 \times \mathrm{PBS}$, EU was detected following the manufacturer's instructions for Click-iT (Invitrogen, Carlsbad, CA, USA), and stained with $5 \mu \mathrm{M}$ DAPI (4',6-diamidino-2-phenylindole; LONZA, Walkersville, ML, USA) for $4 \mathrm{~min}$. After three washes with PBST $(1 \times \mathrm{PBS}$, $0.05 \% \mathrm{w} / \mathrm{v}$ Tween 20 ), the samples were mounted with mounting medium (50\% (v/v) 2,2'-thiodiethanol (Sigma), $50 \%(\mathrm{v} / \mathrm{v}) 1 \times \mathrm{PBS}$, and $2.5 \%(\mathrm{w} / \mathrm{v}) \mathrm{n}$-propyl gallate)

\section{EU pulse incorporation and release}

5-day-old seedlings of $A$. thaliana (Col-0) were used in these experiments. The seedlings were incubated in liquid $1 / 2$ MS medium containing $1 \%(\mathrm{w} / \mathrm{v})$ sucrose and $1 \mathrm{mM} \mathrm{EU}$ (Jena Bioscience) for 2, 5, 15, and $30 \mathrm{~min}$ in the dark. To analyze EU release, seedlings were incubated for $30 \mathrm{~min}$ in medium containing EU. The seedlings were washed with EU-free medium, after which they were incubated in EUfree medium for $1.5,2,3,4$, and $5 \mathrm{~h}$. The EU was detected as described earlier.

\section{Nucleolar ID incorporation}

5-day-old seedlings were subjected to temperature stress treatments as described above, and then incubated in Nucleolar-ID-containing medium (1/2 MS, $1 \%$ w/v sucrose, 500 times dilution of Nucleolar ID (Enzo, Farmingdale, NY, USA)) for $30 \mathrm{~min}$. After washing three times with $1 \times$ assay buffer, the seedlings were incubated in $1 \times$ assay buffer for 30 min at $22{ }^{\circ} \mathrm{C}$ in the dark.

\section{Propidium iodide staining}

Propidium iodide (PI; Sigma-Aldrich, Saint Louis Missouri, USA) was diluted (1:100) with distilled water for a final concentration of $10 \mu \mathrm{g} \mathrm{mL}{ }^{-1}$. Seedlings were stained with the PI solution for 2 min in the dark, after which they were examined with a confocal microscope.

\section{Imaging procedure}

The fluorescence of stained samples was detected under a FV1200 confocal laser microscope equipped with a GaAsP detector. Differential interference contrast (DIC) observations were conducted under an upright microscope (BX53, Olympus, Tokyo, Japan) equipped with a DOC camera (Molecular Devices, Sunnyvale, CA, USA).

\section{Imaging analyses}

Images were analyzed with ImageJ (https://imagej.nih.gov/ $\mathrm{ij} /$ ). In the analyses of ActD-treated nuclei, nuclear patterns were classified using the ratio of EU signal intensity. When the average value of EU signal intensity in the nucleolus was stronger than in the nucleoplasm, we defined the nucleolus as $\mathrm{S}$ type. When the average value of EU signal intensity in the nucleolus was equal to or lower than in the nucleoplasm, we defined the nucleolus as $\mathrm{W}$ type.

\section{Results and discussion}

\section{EU incorporation was inhibited by ActD}

To confirm that the EU signals were derived from newly synthesized rRNA, EU was supplied after $1 \mathrm{~h}$ treatment with the rRNA transcription inhibitor ActD, which binds to rDNA and inhibits the binding of RNA polymerase I. ActD concentrations of 5,25 , and $60 \mu \mathrm{g} \mathrm{mL}^{-1}$ were used with reference to previous experiments (Ahn et al. 2016; Dvořáčková et al. 2018; Mishiba et al. 2013). As shown in Fig. 1a, EU was incorporated into the nucleolus under 

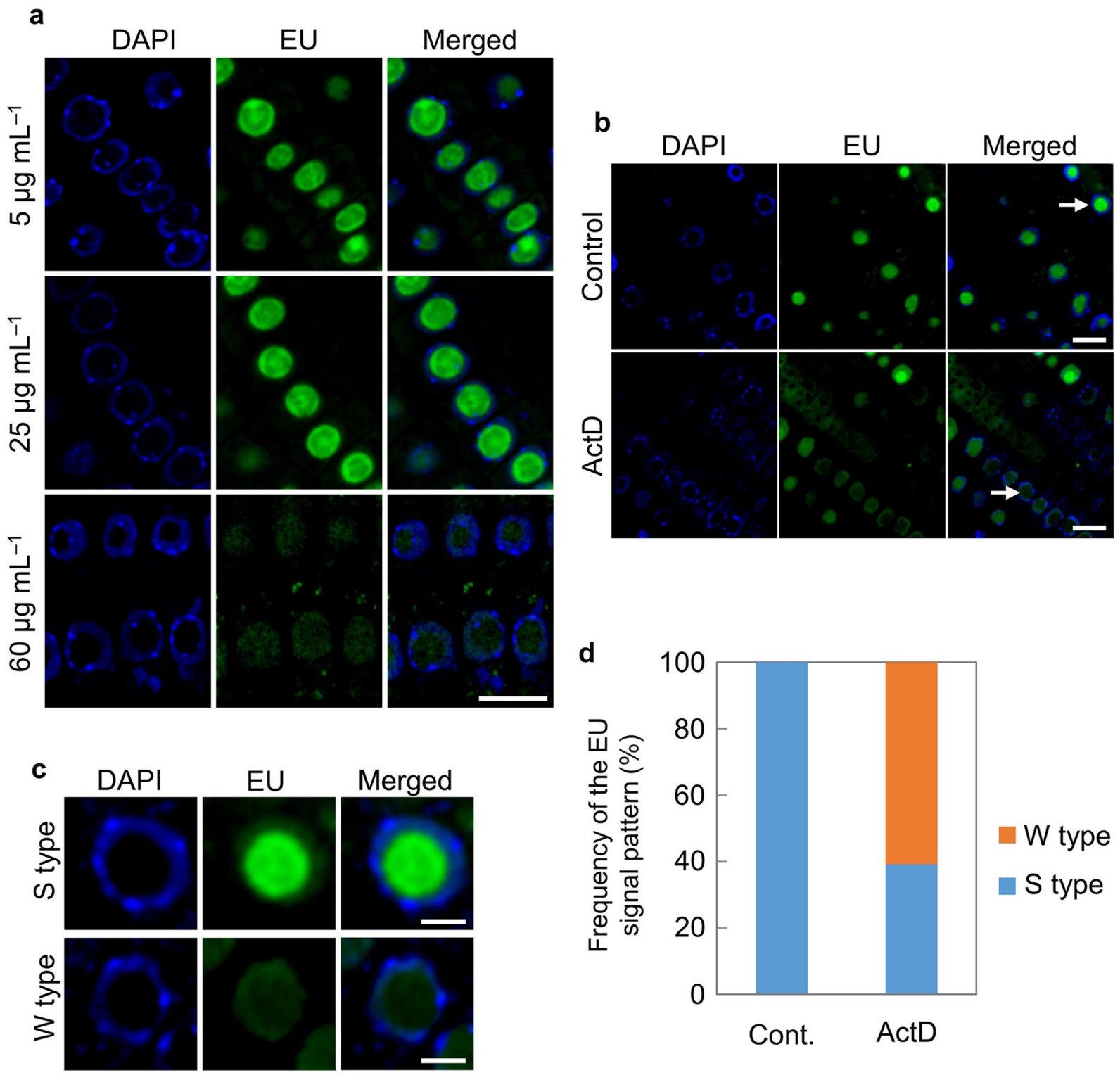

Fig. 1 Distribution of 5-ethynyl uridine (EU) in nucleus of Arabidopsis thaliana root cells. a Root cells of A. thaliana with incorporated EU after ActD treatment; 4',6-diamidino-2-phenylindole (DAPI) staining (left), EU (middle), and merged image (right). Scale bar in the lower right image $=10 \mu \mathrm{m}$. b Comparison of EU signal patterns without (upper) and with ActD treatment (lower). DAPI staining (left), EU (middle), and merged image (right). Scale bar in the lower

5 and $25 \mu \mathrm{g} \mathrm{mL}^{-1}$ ActD, but was not incorporated under $60 \mu \mathrm{g} \mathrm{mL}{ }^{-1}$. In Fig. 1b, EU was supplied in combination with $60 \mu \mathrm{g} \mathrm{mL} \mathrm{m}^{-1}$ ActD. As shown in Fig. 1b, the signal intensity of EU incorporated into the nucleolus was much weaker when it was supplied with ActD than when it was supplied without. Figure $1 \mathrm{c}, \mathrm{d}$ shows the frequency of EU signal patterns classified as strong (S type) and weak (W type). In the S type, the intensity of EU signals was stronger in the nucleolus than in the nucleoplasm. In right image $=10 \mu \mathrm{m}$. $\mathbf{c}$ EU signal patterns classified as S type (strong) (upper) and $\mathrm{W}$ type (weak) (lower). An arrowhead marks the S type in a magnified nucleus from (b, upper) and the $\mathrm{W}$ type in a magnified nucleus from (b, lower). Scale bars $=3 \mu \mathrm{m}$. d Frequency of $\mathrm{S}$ type and $\mathrm{W}$ type EU signals without (control) and with ActD ( $n=69$ for the control and $n=72$ for ActD treatment). The number of the seedlings was 3-5 per experiment

the $\mathrm{W}$ type, the intensity of EU signals in the nucleolus was equal to or weaker than that in the nucleoplasm. The predominance of type $\mathrm{W}$ in the ActD treatment indicated that inhibition of rRNA transcription by ActD reduced the incorporation of EU into newly synthesized rRNA. However, EU signals were observed in the nucleoplasm. Together, these results confirmed that EU was appropriately incorporated into newly synthesized rRNA. 


\section{EU was incorporated by the whole nucleolus, but was released from the center region}

To determine the EU incorporation site in the nucleolus, EU was incorporated into A. thaliana roots for 2, 5, 15, and $30 \mathrm{~min}$ (Fig. 2a). As a result, EU was detected throughout the whole nucleolus in every experiment. The EU signals were unevenly distributed in the nucleolus. To trace the newly synthesized rRNAs, $A$. thaliana roots were incubated in medium lacking EU for 1.5, 2, 4, and $5 \mathrm{~h}$ after an incubation in EU-containing medium for $30 \mathrm{~min}$. The scheme of these experiments is shown in Fig. 2b. As a result, EU was also detected throughout the whole nucleolus at $1.5 \mathrm{~h}$ after EU was released. However, EU signals were weaker at the center region of the nucleolus at the 2 and $3 \mathrm{~h}$ time points. Moreover, EU signals gradually weakened in the nucleolus, but increased in the cytosol region at the 4 and $5 \mathrm{~h}$ time points (Fig. 2c). This result indicated that EU-incorporated rRNAs were transferred from the nucleolus to the cytoplasm between 3 and $4 \mathrm{~h}$ after EU was released.

a

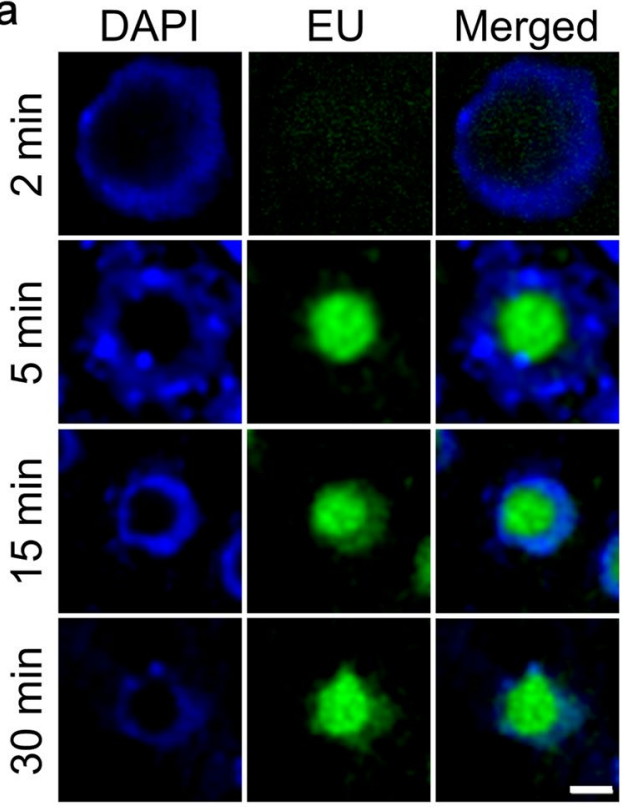

b

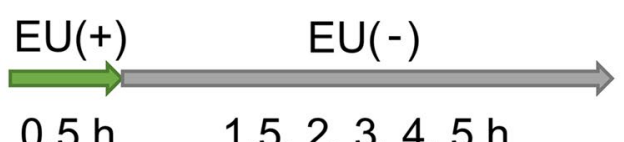

Fig. 2 Short-term incorporation and pulse feeding of 5-ethynyl uridine (EU) into Arabidopsis thaliana root cells. a EU was incorporated into $A$. thaliana roots for $2 \mathrm{~min}, 5,15$, and $30 \mathrm{~min}$. The left panels show 4',6-diamidino-2-phenylindole (DAPI) staining, the middle panels show EU signals, and the right panels show merged images.

\section{EU is not incorporated into the nucleolus center region under heat and chilling stress}

To explore the nucleolar response to various environmental stresses, we monitored the incorporation of EU under low temperature stress (chilling stress: $0{ }^{\circ} \mathrm{C}$ for $2 \mathrm{~h}$, cold stress: $12^{\circ} \mathrm{C}$ for $2 \mathrm{~h}$ ), high temperature stress (mild heat stress: $30{ }^{\circ} \mathrm{C}$ for $2 \mathrm{~h}$, severe heat stress: $37^{\circ} \mathrm{C}$ for $2 \mathrm{~h}$ ), and osmotic stress (200 mM NaCl, 2 h) (Fig. 3a). Following the chilling and severe heat treatments, EU was not incorporated into the center region of the nucleolus. By contrast, EU incorporation occurred similarly to that in the control under cold, mild heat, and osmotic stress. The two patterns of EU signal distribution are shown in Fig. 3b. In pattern I (Fig. 3b upper; magnifications of parts marked with an arrow in Fig. 3a second panel from left), EU was incorporated throughout the whole nucleolus. In pattern II (Fig. 3b lower; magnification of the part marked with an arrowhead in Fig. 3a third panel from right), EU was not incorporated into the center of the nucleolus. Figure $3 \mathrm{c}$ shows the frequency of the EU signal patterns in the stress treatments. Under chilling and severe

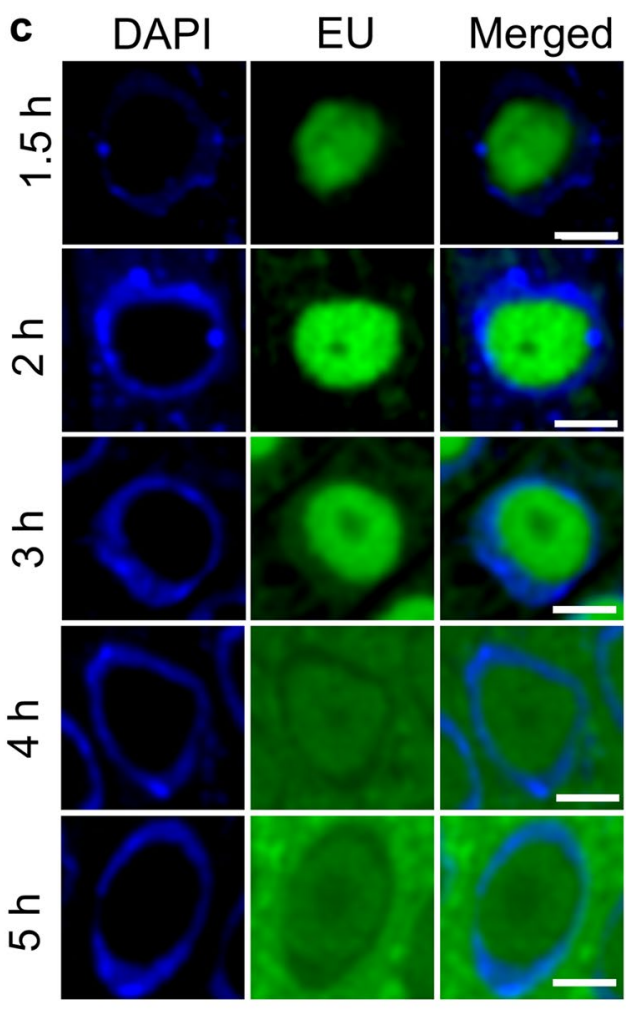

Scale bar $=3 \mu \mathrm{m}$. b Scheme of the EU pulse-feeding experiment. $\mathbf{c}$ Results of pulse feeding at 1.5, 2, 3, 4, and $5 \mathrm{~h}$ after the EU pulse incorporation. The left panels show DAPI signals, the middle panels show EU signals, and the right panels show merged images. Scale bars $=3 \mu \mathrm{m}$ 

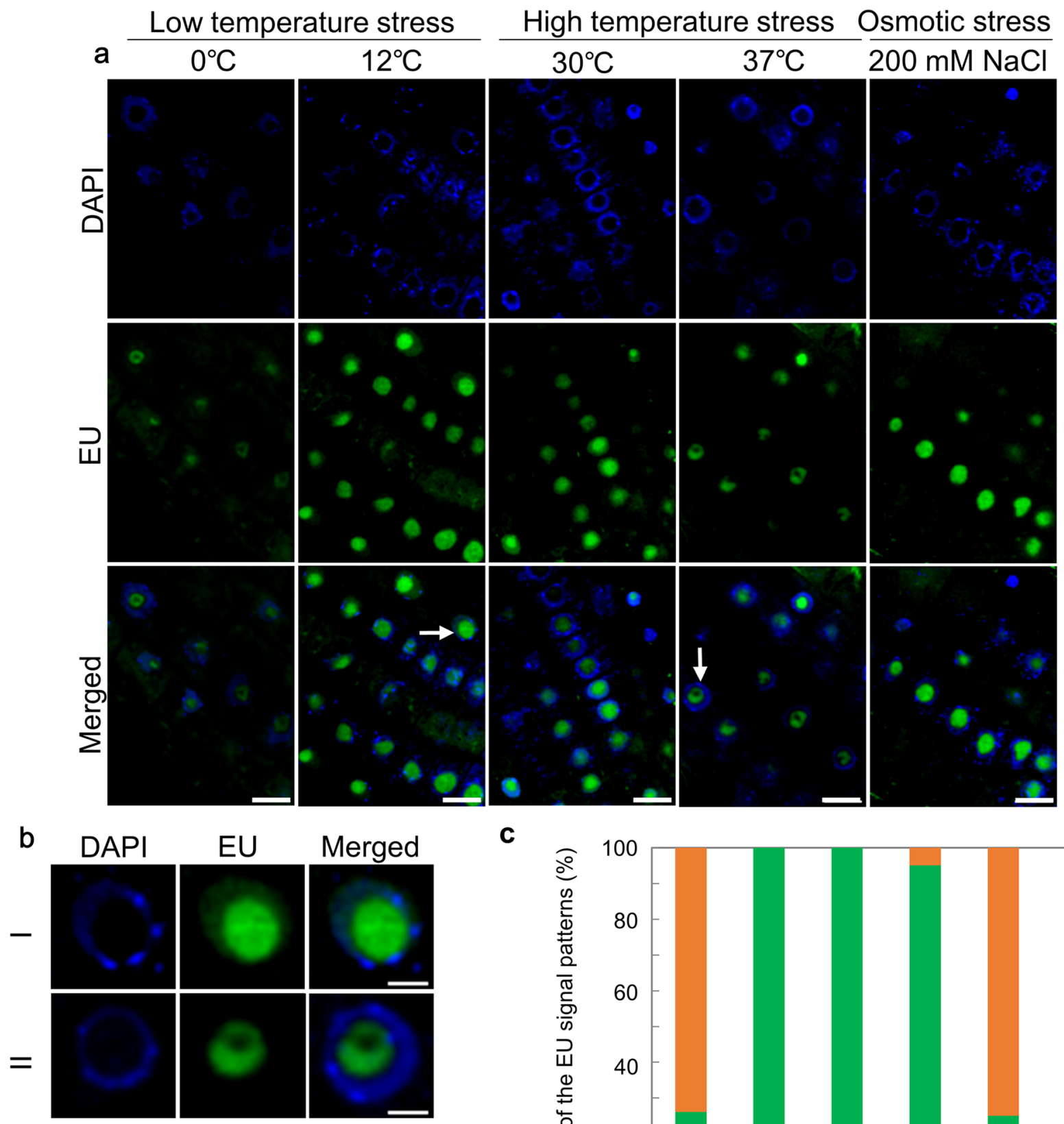

C

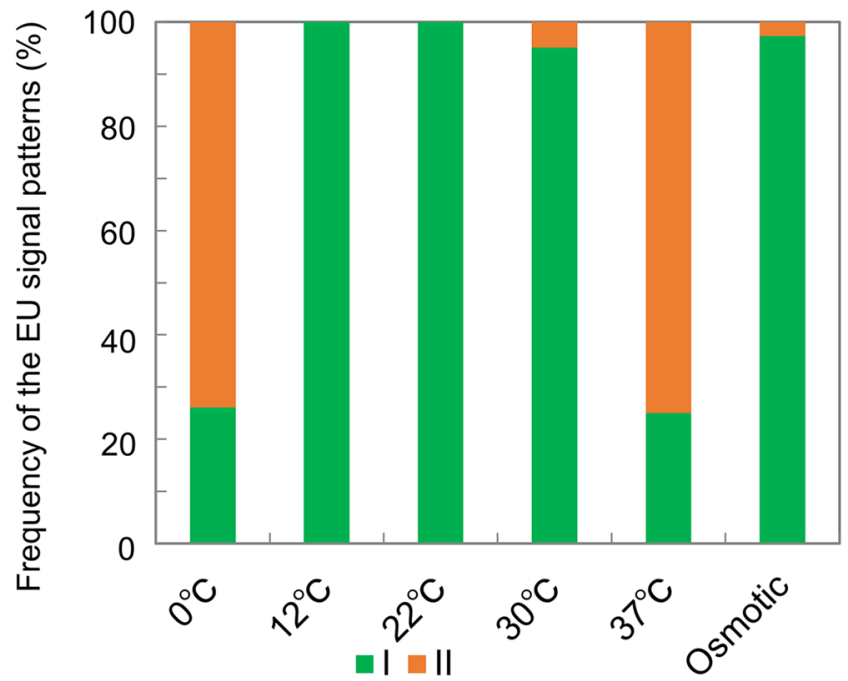

Fig. 3 5-Ethynyl uridine (EU) incorporation under various stress treatments. a EU incorporation under low temperature stress (chilling stress, first left panel; cold stress, second left), high temperature stress (mild heat stress, third left panel; severe heat stress, second right panel), and osmotic stress (first right). The upper panels show 4',6-diamidino-2-phenylindole (DAPI) staining, the middle panels show EU signals, and the lower panels show merged images. Scale bars $=10 \mu \mathrm{m}$. b EU signal patterns classified into patterns I (upper), and II (lower). Pattern I, EU distributed throughout the nucleolus (nucleus marked with arrowhead in (a) second panel from left); pattern II, EU not incorporated into the center region of the nucleolus (nucleus marked with arrowhead in (a) second panel from right). Scale bars $=3 \mu \mathrm{m}$. c Frequency of EU signal patterns under each stress treatment. $n=49$ for control conditions, 74 for cold stress, 23 for chilling stress, 61 for mild heat stress, 28 for severe heat stress, and 37 for osmotic stress. The number of the seedlings was 3-5 per experiment 


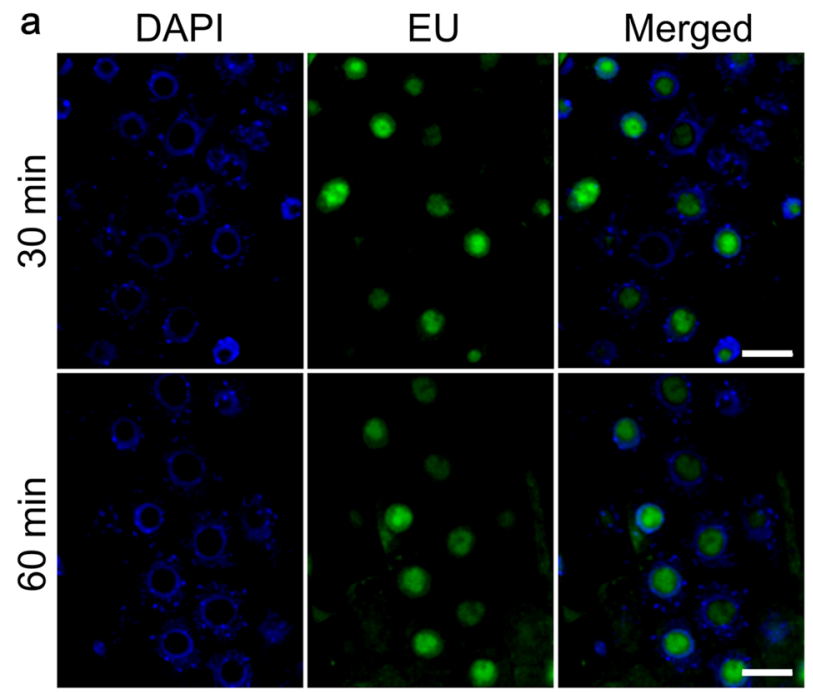

\section{b}

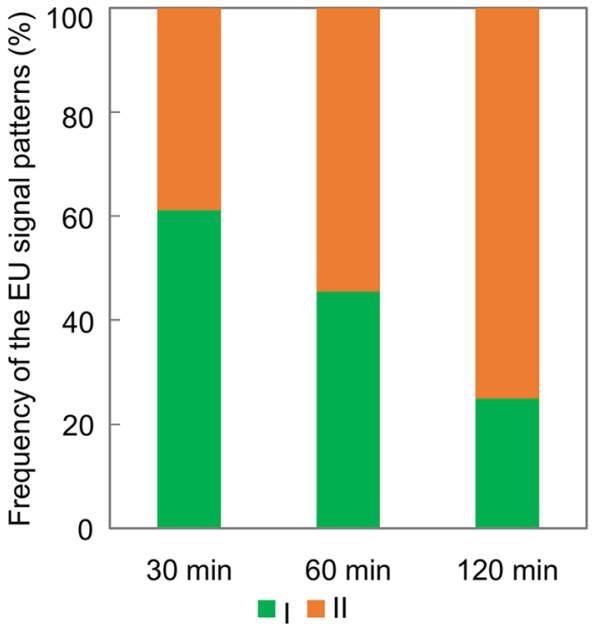

Fig. 4 Time course analyses of EU signal patterns under severe heat stress. a EU incorporation under severe heat stress for $30 \mathrm{~min}$ (upper) and 60 min (lower). The left panels show DAPI staining, the middle panels show EU signals, and the right panels show merged images.

heat stresses, about $60-80 \%$ of the nucleoli showed pattern II.

To analyze the timing of EU incorporation pattern II, EU was incorporated for 30 and 60 min under severe heat stress (Fig. 4a, b). As a result, EU incorporation pattern II gradually increased with increasing stress duration.

\section{Composition of sub-nucleolus structures under heat and chilling stress}

To analyze that the pattern composed under the chilling and severe heat stress were dependent on the EU incorporation, the rRNAs were stained with nucleolar ID (Hasegawa and Matsunaga 2014) (Fig. 5a). As shown in Fig. 5, rRNAs were not localized in the center of the nucleolus under severe heat and chilling stresses. Under these stresses, nucleolar ID signals were also localized in the cytoplasmic region. These signals may indicate the presence of a stress body constructed from mRNAs in the cytoplasm (Chantarachot and Bailey-Serres 2018).

To examine the structure in the center of the nucleolus, seedlings were observed by differential interference contrast (DIC) microscope (Fig. 5b). Under severe heat stress, speckled structures were observed in the nucleolus (Fig. 5b, arrowhead in the middle image). Under chilling stress, a round structure was observed in the center of the nucleolus (Fig. 5b, arrowhead in the right image). To assess whether the chilling and severe heat stresses resulted in irreversible damages, seedlings exposed to these stresses were stained with PI (Fig. 5c). If the seedlings were irreversibly damaged, we expected to detect PI
Scale bars $=10 \mu \mathrm{mm}$ respectively. $\mathbf{b}$ Frequency of EU signal patterns under each stress treatment. The data at $120 \mathrm{~min}$ is the same as shown in the data at $37^{\circ} \mathrm{C}$ in Fig. 3 (c). $n=36$ for $30 \mathrm{~min}$, and 33 for $60 \mathrm{~min}$. The number of the seedlings was $3-5$ per experiment

signals in the nucleus. A lack of PI signals in the nucleus in almost all cells suggested the chilling and severe heat stresses did not irreversibly damage the seedlings. Figure $5 \mathrm{~d}$ shows the summary of the results. These results may indicate that the observed structures inhibited the localization of the newly synthesized and whole rRNAs in the center region of the nucleolus.

The observed structures resembled the sub-nucleolus structure known as the nucleolar cavity or nucleolar vacuole found in soybean (Stępiński 2012), pea (Williams et al. 1985), and Arabidopsis (Ohbayashi et al. 2017). Previous reports showed that the nucleolar vacuole of soybean is small and gradually increases in volume during recovery from chilling stress, and that transcriptional activity increases with increasing volume of the nucleolar cavity (Stępiński 2012, 2014). In contrast to these previous reports, our results showed that nucleolar cavities were formed when chilling or heat stress was imposed. This difference may indicate differences in function between species. U1 snRNP-specific proteins and exon junction complex proteins were found in the nucleolus cavity of $A$. thaliana (Lorković and Barta 2008; Pendle et al. 2005). Conversely, according to our EU and whole-RNA staining results, RNAs were not found in the center region of the nucleolus. Thus, mRNA-related factors such as U1 snRNP and exon junction complex proteins may be collected from the nucleoplasm and stored in the nucleolar cavity to reduce transcriptional events in the nucleoplasm. 

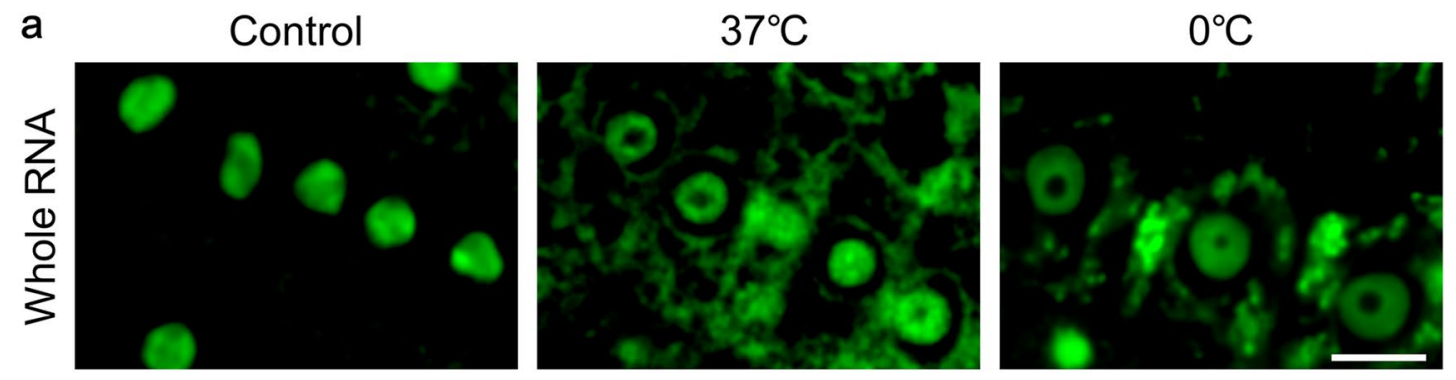

b

Control

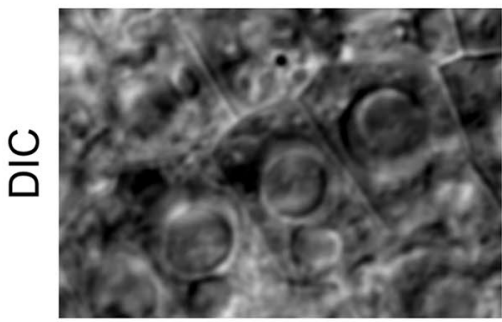

d

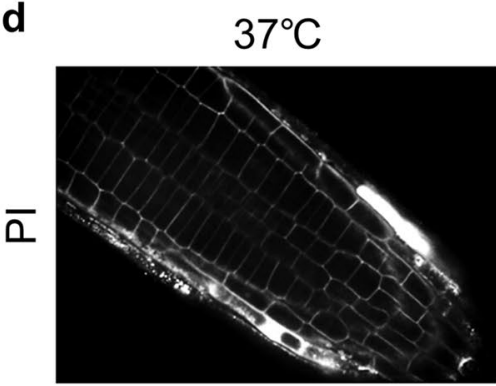

e

Cytosol Nucleus Nucleolus
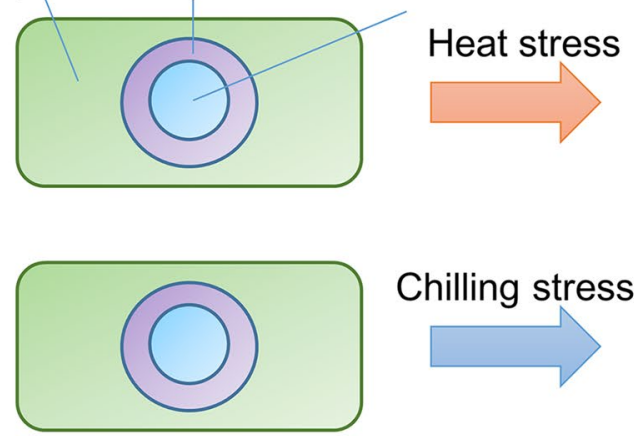

Fig. 5 Observation of sub-nucleolus structures with Nucleolar ID and differential interference contrast imaging. a Nucleolar ID staining images in the control (left), heat stress treatment (middle), and chilling stress treatment (right). b The result of differential interference contrast. Images in the control (left), heat stress treatment (middle), and chilling stress treatment (right). Arrowheads indicate the speck-

$$
37^{\circ} \mathrm{C}
$$
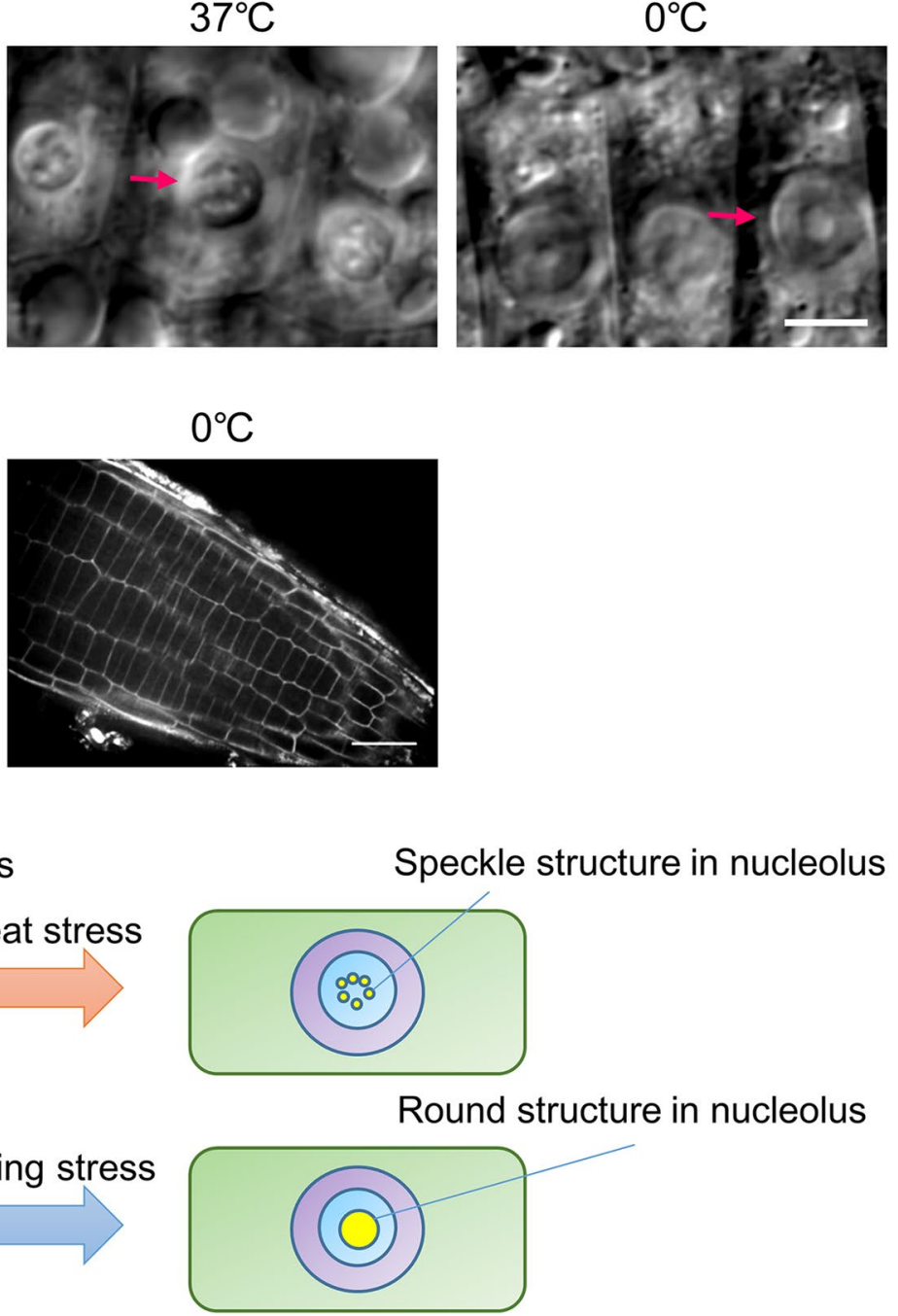

led nucleolar structure in the lower middle image and round nucleolar structure in the lower right image. Scale bars $=10 \mu \mathrm{m}$. c Results of the propidium iodide staining of samples exposed to severe heat and chilling stresses. Scale bar $=50 \mu \mathrm{m}$. d Schematic of plant nucleolar dynamics under heat and chilling stresses 
Acknowledgements This research was supported by MXT/JSPS KAKENHI (15H05955 and 15H05962) for SM. We thank Jennifer Smith, $\mathrm{PhD}$, from Edanz Group (http://www.edanzediting.com/ac) for editing a draft of this manuscript.

\section{References}

Ahn CS, Cho HK, Lee DH, Sim HJ, Kim SG, Pai HS (2016) Functional characterization of the ribosome biogenesis factors PES, BOP1, and WDR12 (PeBoW), and mechanisms of defective cell growth and proliferation caused by PeBoW deficiency in Arabidopsis. J Exp Bot 5217:5232-5267. https://doi.org/10.1093/jxb/erw288

AI-Baker EA, Oshin M, Hutchison CJ, Kill IR (2005) Analysis of UVinduce damage and repair in young and senescent human dernal fibroblasts using the comet assay. Mech Ageing Dev 126:664-672. https://doi.org/10.1016/j.mad.2004.12.002

Andrade LE, Tan EM, Chan EK (1993) Immunocytochemical analysis of the coiled body in the cell cycle during cell proliferation. Proc Natl Acad Sci USA 90:1947-1951

Boisvert FM, van Koningsbruggen S, Navascues J, lamond AI (2007) The multifunctional nucleolus. Nat Rev Mol Cell Biol 8:457-470. https://doi.org/10.1038/nrm2184

Boulon S, Westman BJ, Hutten S, Boisvert FM, Lamond AI (2010) The Nucleolus under Stress. Mol Cell 40. https://doi.org/10.1016/j. molcel.2010.09.024

Carmo-Fonseca M, Ferreira J, Lamond AI (1993) Assembly of snRNPcontaining coiled bodies regulated in interphase and mitosis evidence that the oiled body is a kinetic nuclear structure. J Cell Biol 120:841-852

Chantarachot T, Bailey-Serres J (2018) Polysomes, stress granules, and processing bodies: a dynamic triumvirate controlling cytoplasmic mRNA fate and function. Plant Physiol 176:254-269. https://doi. org/10.1104/pp.17.01468

Cioce M, Boulon S, Matera AG, Lamond AI (2006) UV-induced fragmentation of Cajal bodies. J Cell Biol 175:401-413. https://doi. org/10.1083/jcb.200604099

Dvořáčková M, Fajkus J (2018) Visualization of the nucleolus using ethynyl uridine. Front Plant Sci 9:177. https://doi.org/10.3389/ fpls.2018.00177

Greco A (2009) Involvement of the nucleolus in replication of human viruses. Rev Med Virol 19:201-214. https://doi.org/10.1002/ rmv. 614

Handwerger KE, Wu Z, Murphy C, Gall JG (2002) Heat shock induce mini-cajal bodies in the Xenopus germinal vesicle. J Cell Sci 115:2011-2020

Hasegawa J, Matsunaga S (2014) Morphology of nucleoli in tobacco BY-2 cultured cells. In: Noguchi T, Kawano S, Tsukaya H, Matsunaga S, Sakai A, Karahara I, Hayashi Y (eds) Atlas of plant cell structure, 1st edn. Springer, Tokyo, pp 4-5

Hayashi K, Hasegawa J, Matsunaga S (2013) The boundary of the meristematic and elongation zones in roots: endoreduplication precedes rapid cell expansion. Sci Rep. https://doi.org/10.1038/ srep02723

Hoppe S, Bierhoff H, Cado I, Weber A, Tiebe M, Grumm I, Voit R (2009) AMP-activated protein ligase adapts rRNA synthesis to cellular energy supply. Proc Natl Acad Sci USA 106:1778117786. https://doi.org/10.1073/pnas.0909873106

Ichihashi Y, Kawade K, Usami T, Horiguchi G, Takahashi T, Tsukaya $\mathrm{H}$ (2011) Key proliferative activity in the junction between the leaf blade and leaf petiole of Arabidopsis. Plant Physiol 157:11511162. https://doi.org/10.1104/pp.111.185066

James MJ, Zomerdijk JC (2010) The role of Cajal bodies in the expression of late phase adeovirus proteins. Virology 399:299-311. https ://doi.org/10.1016/j.virol.2010.01.013
Kant P, Kant S, Gordon M, Shaked R, Barak S (2014) STRESS RESPONSE SUPPRESSOR 1 and STRESS RESPONSE SUPPRESSOR2, two DEAD-Box RNA helicases that attenuate Arabidopsis responses to multiple abiotic stresses. Plant Physiol 145:814-830. https://doi.org/10.1104/pp.107.099895

Kotogány E, Dudits D, Horváth GV, Ayaydin F (2010) A rapid and robust assay for detection of S-phase cell cycle progression in plant cells and tissues by using ethynyl deoxyuridine. Plant Method 6:1746. https://doi.org/10.1186/1746-4811-6-5

Kruhlak M, Crouch EE, Orlov M, Montano C, Gorski SA, Nussenzweig A, Misteli T, Phair RD, Casellas R (2007) The ATM repair pathway inhibits RNA polymerase I transcription in response to chromosome breaks. Nature 447:730-734. https://doi.org/10.1038/ nature 05842

Lorković ZJ, Barta A, Jin D-Y (2008) Role of Cajal bodies and nucleolus in the maturation of the U1 snRNP in Arabidopsis. PLoS ONE 3:e3989

Matsunaga S, Katagiri Y, Nagashima Y, Sugiyama T, Hasegawa J, Hayashi K, Sakamoto T (2013) New insights into the dynamics of plant cell nuclei and chromosomes. IRCMB 305:1937-6448. https://doi.org/10.1016/B978-0-12-407695-2.00006-8

Mayer C, Grummt I (2006) Ribosome biogenesis and cell growth: mTOR coordinates transcription by all three classes of nuclear RNA polymerases. Oncogene 25:6384-6391. https://doi. org/10.1038/sj.onc.1209883

Mekhail K, Rivero-Lopez L, Khacho M, Lee S (2006) Restriction of rRNA synthesis by VHL maintains energy equilibrium under hypoxia. Cell Cycle 5:240-2413. https://doi.org/10.4161/ cc.5.20.3387

Mishiba K, Nagashima Y, Suzuki E, Hayashi N, Ogata Y, Shimada Y, Koizumi N (2013) Defects in IRE1 enhance cell death and fail to degrade mRNAs encoding secretory pathway proteins in the Arabidopsis unfolded protein response. Proc Natl Acad Sci USA 110:5713-5718. https://doi.org/10.1073/pnas.1219047110

Morency E, Sabra M, Catez F, Texier P, Lomote P (2007) A novel cell response triggered by interphase centromere structural instability. J Cell Biol 177:757-768. https://doi.org/10.1083/jcb.200612107

Ohbayashi I, Sugiyama M (2018) Plant nucleolar stress response, a new face in the NAC-dependent cellular stress responses. Front Plant Sci 8:2247. https://doi.org/10.3389/fpls.2017.02247

Ohbayashi I, Lin CY, Shinohara N, Matsumura Y, Machida Y, Horiguchi G, Tsukaya H, Sugiyama M (2017) Evidence for a role of ANAC082 as a ribosomal stress response mediator leading to growth defects and developmental alterations in Arabidopsis. Plant Cell 29:2644-2660. https://doi.org/10.1105/tpc.17.00255

Pendle AF, Clark GP, Boon R, Lewandowska D, Lam YW, Andersen J, Mann M, Lamond AI, Brown JWS, Shaw PJ (2005) Proteomic analysis of the Arabidopsis nucleolus suggests novel nucleolar functions. Mol Biol Cell 16:260-269

Pontvianne F, Blevins T, Chandrasekhara C, Mozgová I, Hassel C, Pontes OM, Tucker S, Mokros P, Muchová V, Fajkus J, Pikaard CS (2013) Subnuclear partitioning of rRNA genes between the nucleolus and nucleoplasm reflects alternative epiallelic states. Genes Dev 27:1545-1550. https://doi.org/10.1101/gad.22164 8.113

Rebelo L, Almeida F, Ramos C, Bohmann K, Lamond AI, CarmoFonseca M (1996) The dynamics of coiled bodies in the nucleolus of adenovirus-infected cells. Mol Biol Cell 7:1137-1151

Rubbi CP, Miler J (2003) Disruption of interruption of the nucleolus mediates stabilization of p53 in response to DNA damages and other stress. EMBO J 22:6068-6077. https://doi.org/10.1093/ emboj/cdg 579

Russo A, Russo G (2017) Ribosomal proteins control or bypass p53 during nucleolar stress. Int Mol Sci. https://doi.org/10.3390/ijms1 8010140 
Salic A, Mitchison TJ (2008) A chemical method for fast and sensitive detection of DNA synthesis in vivo. Proc Natl Acad Sci 105:2415-2420. https://doi.org/10.1073/pnas.0712168105

Sirri V, Urcuqui-Inchima S, Roussel P, Hernandez-Verdun D (2008) Nucleolus: the fascinating nuclear body. Histchem Cell Biol 129:13-31. https://doi.org/10.1007/s00418-007-0359-6

Stępiński D (2012) Immunofluorescent localization of ubiquitin and proteasomes in nucleolar vacuoles of soybean root meristematic cells. Eur J Histchem 56:71-77. https://doi.org/10.4081/ejh.2012. e13

Stępiński D (2014) Functional ultrastructure of the plant nucleolus. Protoplasm 251:1285-1306

Tanaka Y, Okamoto K, Teye K, Umata T, Yamagiwa N, Suto Y, Zhang Y, Tsuneoka M (2010) JmjC enzyme KDM2A is a regulator of
rRNA transcription in response to starvation. EMBO J 29:1510 1522. https://doi.org/10.1038/emboj.2010.56

Williams LM, Charest PM, Lafontaine JG (1985) Nuclease-gold and protease-gold labelling over the nucleolar vacuoles of pea root tip cells. Biol Cell 55:21-26

Yokoyama R, Hirakawa T, Hayashi S, Sakamoto T, Matsunaga S (2016) Dynamics of plant DNA replication based on PCNA visualization. Sci Rep. https://doi.org/10.1038/srep29657

Publisher's Note Springer Nature remains neutral with regard to jurisdictional claims in published maps and institutional affiliations. 